\title{
Optimization design of mobile welding workshop
}

\section{Jianping Chen ${ }^{1,2, a}$, Shengsun $\mathrm{Hu}^{1,2, b}$, Junqi Shen ${ }^{1,2, \mathrm{c}}$}

\author{
${ }^{1}$ Tianjin Key Laboratory of Advanced Joining Technology, Tianjin University, Tianjin 300072, China \\ ${ }^{2}$ School of Materials Science and Engineering, Tianjin University, Tianjin 300072, China \\ aHB-JP@163.com, bhuss@tju.edu.cn, cshenjunqi@tju.edu.cn
}

Keywords: mobile welding workshop, optimization design, structure design, transmission design

\begin{abstract}
Mobile welding workshop is an indispensable engineering machinery of pipeline construction. Optimization design of structure and transmission of mobile welding workshop was researched. The operating weight of designed vehicle is two tons less than the existing mobile welding workshop and the width is reduced from $2400 \mathrm{~mm}$ to $2200 \mathrm{~mm}$ by optimization design. The welding test results show that the designed mobile welding workshop can meet the needs of practical engineering.
\end{abstract}

\section{Introduction}

With the high-speed development of pipeline construction, pipe construction equipments have been developed rapidly. Welding is an important part of the pipeline construction, so its quality is directly related to the efficiency and security of pipeline transport. Pipeline welding technology can be divided into four stages: upward welding of SMAW, downward welding of SMAW, semiautomatic welding and automatic welding [1-6]. At the present stage, core electrode semiautomatic welding method is widely used in long distance transport pipeline construction by virtue of high welding pass rate and production efficiency [7]. As an indispensable engineering machinery of pipeline semi-automatic welding production, mobile welding workshop could improve the efficiency of pipeline construction and reduce construction cost, which has been regarded importance by the researchers of pipeline construction equipment.

Now, mobile welding workshop at home and abroad, whether mechanical driving mode or full hydraulic drive mode, has the following problems:

(1) The engine and generation device are separated with transfer case or belt driving, which led to inefficiency, large-vibration, wide-noise and high energy consumption.

(2) The jumbo size of existing mobile welding workshop brings about some disadvantagedifficult to transport, poor maneuverability, the limitation of narrow area.

To solve the problems of existing mobile welding workshop, a new type of energy saving and silenced integrated mobile welding workshop is developed. The related issues are researched. The main research content is as follow:

(1) The design of the mobile welding workshop was optimized. The travel system, derrick system and power welding system were researched. The high-efficiency driving mode in engine, power welding multifunction, lorry-mounted crane, and running system were determined. The modular design of mobile welding workshop was realized.

(2) The structure of mobile welding workshop was optimized. Contour dimension and operating weight of the mobile welding workshop were curtailed.

(3) The energy saving and silenced integrated mobile welding workshop was used to do welding procedure test.

\section{Optimization design}

The mobile welding workshop is mainly composed of engine, hydraulic system, chassis, lorry-mounted crane, generator, electric welding machine and cab, as shown in Fig.1. 


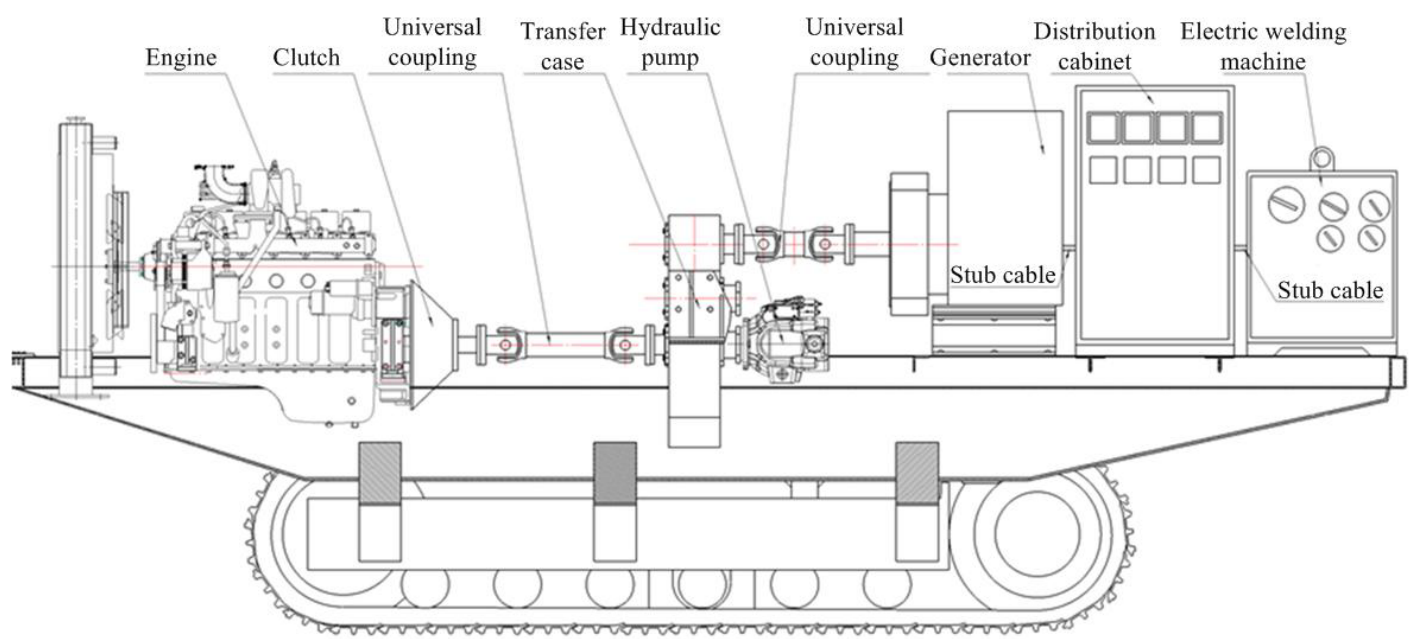

Fig.1 The structure diagram of mobile welding workshop

The universal mobile welding workshops all use an engine to drive travel mechanisms and generator through mechanical transfer case. The generator can supply electric energy for two DC400 arc welding power. Because the walking system and the electric welding machine of mobile welding workshop use one engine, the power of engine should be more than $100 \mathrm{~kW}$ to meet the power requirement of walking part. But only 50kW engine power could meet the need of actual welding. During site operation, the walking time of mobile welding workshop is about an hour, and the welding time is more than 8 hour. Therefore, engine is in high energy consumption state when welding. The used engines all are engineering machinery dedicated engine with $8 \%$ speed governing rate, which can not meet the request that the speed governing rate is less than $5 \%$ for welding, so the voltage fluctuation from the engine is large, and the welding quality is not stable. In addition, because of the transfer case mechanical structure used, the connecting device is complexity, the fault point of system is increased, the reliability is reduced, and the fault rate of mobile welding workshop will be increased.

The energy saving mute mobile welding workshop adopted single power structure, in which the power of the crawler walk chassis, lorry-mounted crane and generator-welding is offered by one engine. The generator of the generator-welding unity machine offers welding power and takes charge of the driving of mobile welding workshop at the same time, and the welding and driving do not affect each other. The welding power adopted HW800DS generator-welding unity machine which could perform melting polar semi-automatic gas shielded arc welding or SMAW with two wire feeding machine or two electrode holder. SMAW and melting polar semi-automatic gas shielded arc welding also can work at the same time. The working noise and fuel consumption is lower than other engineering vehicles.

Fig. 2 is the structure diagram of energy saving mute mobile welding workshop.

The energy saving mute mobile welding workshop adopts the transmission mode of direct-connected engine, generator and hydraulic pump, as shown in Fig.3. When the engine work, the hydraulic pump is idling; when the hydraulic pump work, the generator shaft is rotating driven by the engine, at the same time the engine is not working, the hydraulic pump is working driven by generator shaft. The generator and welding machine chose advanced generator-welding unity machine which avoid the complex connection structure of transfer case and distribution box. This approach improves the transmission efficiency and reduces energy consumption, failure rate of the mobile welding workshop and construction cost significantly. 


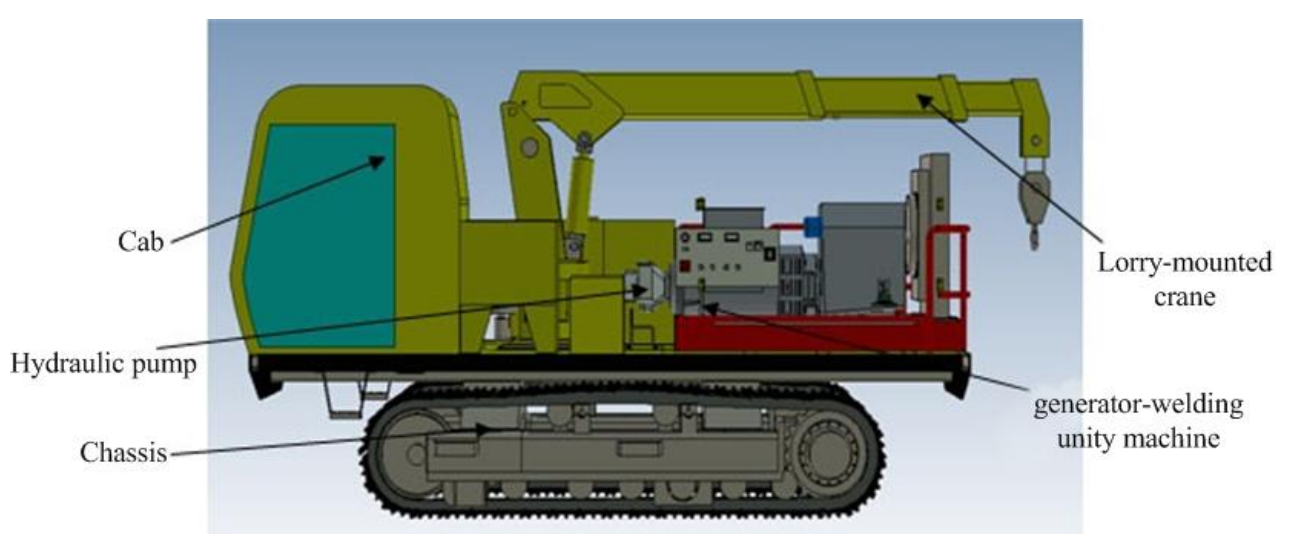

Fig.2 The structure diagram of energy saving mute mobile welding workshop

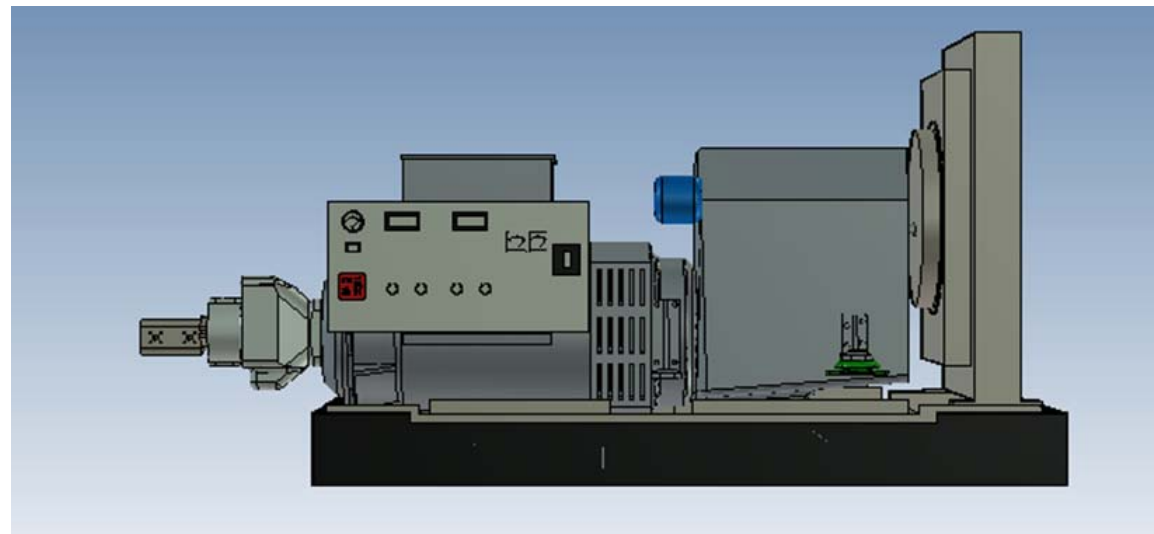

Fig.3 The transmission structure of energy saving mute mobile welding workshop

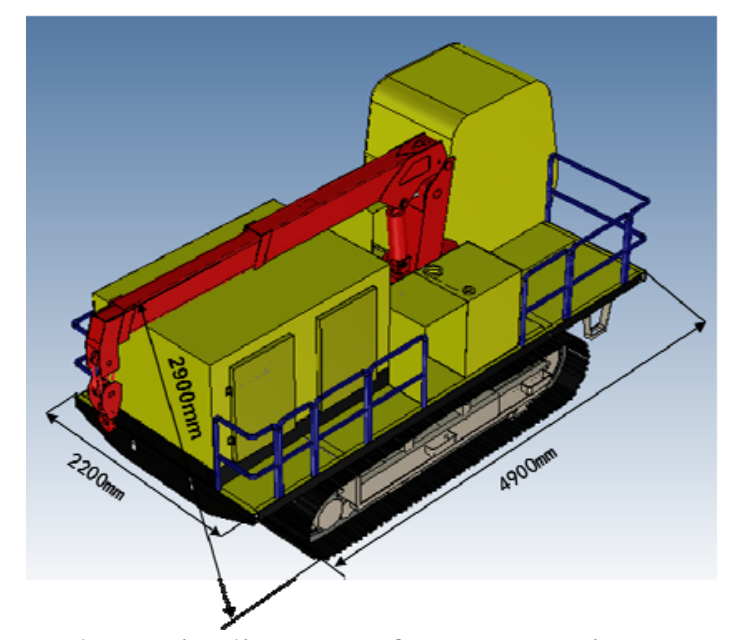

Fig.4 The overall dimension schematic diagram of energy saving mute mobile welding workshop In order to reduce the high transportation cost and improve the vehicle agility through the narrow area, the contour dimension and operating weight of the energy saving mute mobile welding workshop must be reduced. As generator-welding unity machine, the walk and welding of the vehicle form two separate units which simplify the overall structure and realize the structure modular of mobile welding workshop. The design method improves the reliability and creates the prerequisite of overall size reduction, flexibility increase and practicality of the mobile welding workshop. The dimension schematic diagram of energy saving mute mobile welding workshop is shown in Fig.4.

The operating weight of designed vehicle is two tons less than the existing mobile welding workshop and the width is reduced from $2400 \mathrm{~mm}$ to $2200 \mathrm{~mm}$ which is suit to the requirements of the semi-trailer transport. The bolt-on connection is adopted between the walk chassis and the generator-welding unity machine which is convenient to disassembly and maintenance. 


\section{Welding experiment}

The SMAW welding process test for 9\% Ni steel and semi-automatic welding process test of X80 steel large diameter pipeline is carried out by using the designed energy saving mute mobile welding workshop. By using of different welding methods, welding tests are made with different base metals and welding materials, and this approach extent to mountains and foothills areas which prove the preponderance of the device and receive the valuable welding qualification results.

\section{Conclusions}

This article researches the optimization design for welding engineering vehicle with analysis of walking system, derrick system and power welding system. The efficient dynamic transmission mode of engines, generator-welding unity machine, lorry-mounted crane and walking system is determined and the modular design of mobile welding workshop is realized. The reliability of the equipment is improved and the effect of energy-saving and noise reduction is achieved.

The structure of the mobile welding workshop is optimized by reducing the height and width, which solves the difficulties of transport and agility.

In the actual welding situation, the welding tests of energy saving mute mobile welding workshop are made. The results show that: the design of energy saving mute mobile welding workshop meet the requirements with $40 \%$ energy consumption reduction. The working noise is less than $70 \mathrm{~dB}$. The machine stability is good when climbing with maximum bearing, which meet the actual project needs. At the same time, the transportation cost is lower than before.

\section{References}

[1] Y.L. Sui and D.M. Sun: Welded Pipe and Tube. 2000, 2, 1-3. In Chinese

[2] S.L. Liu, J. Ma, Y.L. Sui, H.L. Zeng, Z. Yan and J.J. Li: Welding Technology. 2000, S1, 47-48. In Chinese.

[3] B. Wang: Welding Technology. 2000, 3, 34-81. In Chinese

[4] B. Wang: Electric Welding Machine. 2000, 2, 1-6. In Chinese

[5] Z.K. Xue and Y.L. Sui: Welding Technology. 2001, S2, 16-18. In Chinese

[6] J.S. Li, Z.Y. Du and C.W. Sun: Welding Technology. 2001, 1, 22-23. In Chinese

[7] M.H. Liu, Y. Ai and Z.W. Zuo: Petrochemical Equipment. 2005, 2, 63-64. In Chinese 